\title{
Lumen-apposing covered self-expanding metal stent for management of benign gastrointestinal strictures
}

Authors

Institution
Shounak Majumder, Navtej S. Buttar, Christopher Gostout, Michael J. Levy, John Martin, Bret Petersen, Mark Topazian, Louis M. Wong Kee Song, Barham K. Abu Dayyeh

Mayo Clinic - Division of Gastroenterology and Hepatology, Rochester, Minnesota, USA submitted 6. October 2015 accepted after revision 8. October 2015

\section{Bibliography}

Dol http://dx.doi.org/

10.1055/s-0041-108195

Published online: 15.12.2015

Endoscopy International Open 2016; 04: E96-E101

(c) Georg Thieme Verlag KG

Stuttgart · New York

E-ISSN 2196-9736

\section{Corresponding author}

Barham K. Abu Dayyeh, MD

Mayo Clinic - Division of

Gastroenterology and

Hepatology

200 First Street SW

Rochester

Minnesota 55905

USA

Fax: +1-507-538-5820

abudayyeh.barham@mayo.edu
Background and aims: Self-expanding metal stents (SEMS) are safe and effective for endoscopic management of malignant gastrointestinal strictures, but there is limited experience with their use in refractory benign strictures. We assessed the use of a new lumen-apposing covered SEMS for the management of benign gastrointestinal strictures.

Methods: A single-center case-series of five patients who underwent lumen-apposing covered SEMS placement for benign gastrointestinal strictures.

Results: Three patients had a benign gastroduodenal stricture, one had a distal colonic anasto-

\section{Introduction}

$\nabla$

Endoscopic balloon dilation (EBD) is a common initial treatment for benign gastrointestinal strictures, and is safe and effective in the short-term, but often requires multiple sessions, and strictures frequently recur $[1,2]$. Fully covered self-expanding metal stents (fcSEMS) relieve the symptoms of refractory benign gastrointestinal strictures [3], but stent migration and intolerance are major limitations $[4,5]$, and strictures frequently recur after stent removal [6].

Lumen-apposing fully covered SEMS (LA-SEMS) consist of a barbell-shaped, flexible nitinol stent designed for deployment through a therapeutic linear echoendoscope ( $\bullet$ Fig. 1 a). In this series, we describe the use of LA-SEMS for the management of selected benign gastrointestinal strictures and discuss the benefits and limitations of this approach. motic stricture, and one with complete gastrojejunal anastomotic stenosis underwent endoscopic creation of a new gastrojejunostomy. None of the patients developed any immediate or delayed stent-related adverse events. In two patients, the stents were left in place indefinitely. Stents were removed from the other three patients with successful resolution of their symptoms during follow-up.

Conclusion: Lumen-apposing, fully covered SEMS appear to be safe and effective for management of selected benign gastrointestinal strictures.

\section{Case series}

We retrospectively identified all cases of benign gastrointestinal luminal stenosis treated with placement of a LA-SEMS (Axios $15 \mathrm{~mm}$; Xlumena, Mountain View, CA, USA) at our institution between November 2014 and April 2015, and reviewed patient medical records and images. The protocol was approved by the Mayo Clinic Rochester IRB.

\section{Case 1}

A 45-year-old woman was referred for treatment of a benign pyloric stricture which had recurred after prior EBD. An upper gastrointestinal series demonstrated a short stricture of the pyloric channel which could not be traversed endoscopically ( $\bullet$ Fig.2a, $\bullet$ Fig.2b). Under fluoroscopic guidance, a LA-SEMS was deployed across the pyloric stenosis and dilated to $15 \mathrm{~mm}(\bullet \mathrm{Fig} .2 \mathrm{c}$ ). Her symptoms resolved, and the stent was removed endoscopically 3 months later ( $\mathbf{F i g} . \mathbf{2 d}$ ). The previously strictured area was widely patent and allowed easy passage of the endoscope. Symptoms have not recurred during 3 months of follow-up after stent removal. 

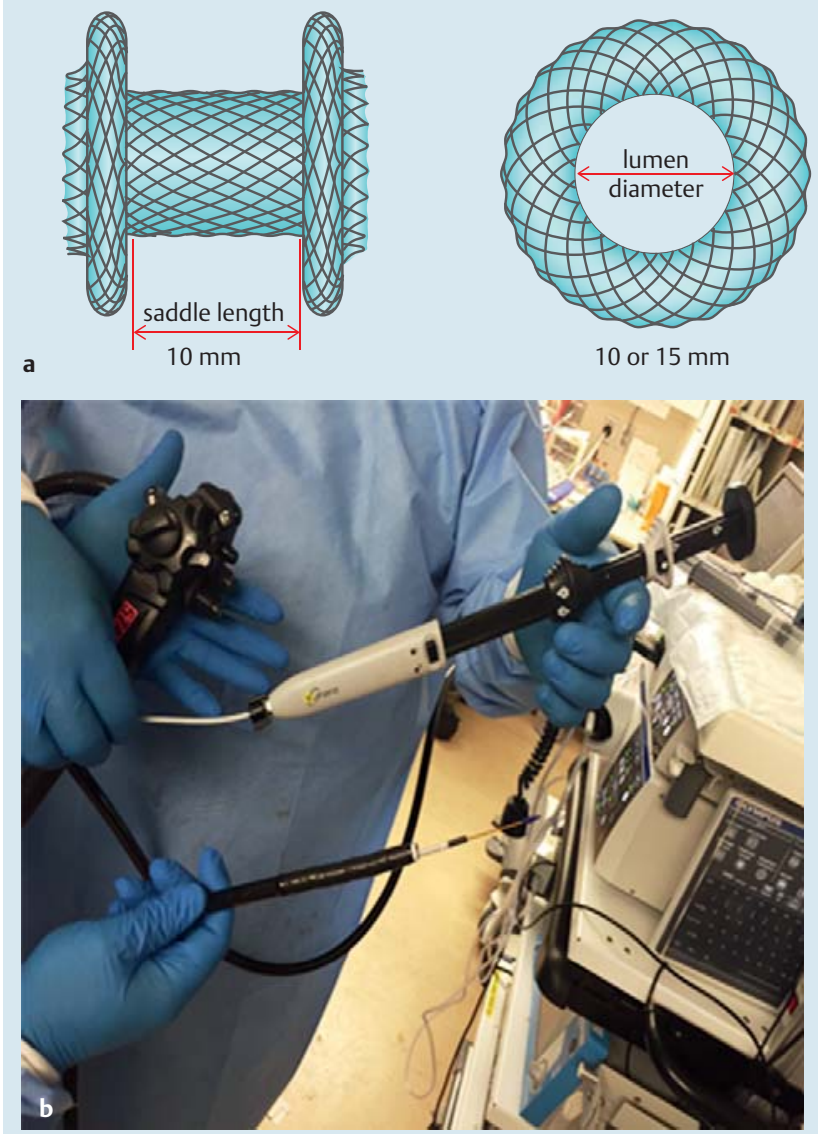

Fig. 1 a The lumen-apposing, double-flanged, fully-covered SEMS. b The delivery system of the stent inserted through a forward viewing gastroscope with a therapeutic channel. Notice that the assistant needs to stabilize the shaft of the delivery system of the stent, and that deploying the stent with a forward-viewing gastroscope requires two operators.

\section{Case 2}

A 24-year-old woman with a history of Roux-en-Y gastric bypass was referred for management of a gastrojejunostomy stricture. EBD at another hospital had been complicated by contained perforation. Esophagogastroduodenoscopy (EGD) showed a 4-cm long anastomotic stricture ( Fig.3a, $\bullet$ Fig.3b). Initially, an $18-\mathrm{mm} \times 15.3-\mathrm{cm}$ fcSEMS was placed which was removed after 1 month due to non-tolerance, and a symptomatic stricture subsequently recurred. An LA-SEMS was placed with the proximal flange in the gastric pouch, and the distal flange partially opened within the stricture ( $\bullet$ Fig. $3 \mathrm{c}$ ). To fully bridge the long stricture, a second LA-SEMS stent was placed in an overlapping fashion ( $\bullet$ Fig. 3 d), and both stents were dilated to $15 \mathrm{~mm}$. A follow-up upper gastrointestinal series and EGD at 6 weeks showed a widely patent gastrojejunostomy with excellent stent position ( $\bullet$ Fig. 3 e, $\bullet$ Fig.3f). In view of high surgical risk, a shared decision was made to leave the two LA-SEMS in place indefinitely. During 3 months of follow-up, she continues to be symptom-free.

\section{Case 3}

A 51-year-old woman presented for management of an anastomotic leak. She had previously undergone bariatric Roux-en-Y gastric bypass and subsequent revision gastrojejunostomy. EGD showed an edematous gastric pouch and complete anastomotic stenosis precluding access to the jejunum ( $\bullet$ Fig.4a). A singleballoon enteroscope was inserted into the excluded distal stomach via an existing gastrostomy tube, and advanced in a retrograde fashion to the anastomosis ( $\nabla$ Fig.4b). A curvilinear echoendoscope was advanced via the mouth to meet the enteroscope in a rendezvous fashion. The Roux limb was distended with water and punctured under endoscopic ultrasound (EUS) guidance, and the tract was balloon dilated to $6 \mathrm{~mm}$. A LA-SEMS was placed to create a new gastrojejunal anastomosis ( $\bullet$ Fig. 4c, - Fig. 4 d). A contrast study showed no extravasation ( $\bullet$ Fig. 4 e). The vertical staple line leak was closed with an over-the-scope clip. The LA-SEMS was removed at 8 weeks ( Fig.4f). Twelve weeks later, the patient was eating well with no symptoms.

\section{Case 4}

An 83-year-old woman presented for treatment of a pyloric channel peptic stricture which had recurred after EBD. EGD revealed a short pyloric stricture, with a luminal diameter of less than $1 \mathrm{~mm}$ ( Fig.5a). She was deemed a high risk surgical candidate due to her advanced age and poor nutritional status. A LASEMS was placed and the stent lumen was dilated to $12 \mathrm{~mm}$ ( Fig.5b, $\triangle$ Fig.5c, $\triangle$ Fig.5d). She continued to do well 12 weeks after the procedure, with the intent to keep the stent in place indefinitely.

\section{Case 5}

A 34-year-old man with a past history of sigmoid colectomy with an end-to-side colorectostomy was admitted for management of bowel obstruction secondary to a benign anastomotic stricture. Colonoscopy revealed a severely narrowed, short stricture at the anastomotic site ( $\checkmark$ Fig. 6 a). We opted to place a LA-SEMS, since a longer stent would potentially have a higher likelihood of migration and cause excessive patient discomfort due to stent proximity to the anal verge ( $\nabla$ Fig. $\mathbf{6 b}, \nabla$ Fig. $\mathbf{6 c}$ ). The lumen of the stent was dilated up to $12 \mathrm{~mm}$ ( $\bullet$ Fig. $\mathbf{6 d}$ ). The obstruction was relieved and the patient subsequently underwent low anterior resection with diverting loop ileostomy.

\section{Discussion}

$\nabla$

We found that LA-SEMS were effective and safe for the treatment of a variety of benign gastrointestinal stenoses. The stents were easy to deploy and remove, well tolerated, and did not migrate. In contrast to repeated EBD for difficult strictures, patients in this series required at most two endoscopies, and the fully covered stents potentially mitigate the risk of perforation associated with endoscopic treatment.

Several studies have described the use of SEMS for the management of benign gastrointestinal strictures [4,7-9]. The technical success of SEMS placement in these series approaches $100 \%$ with reported clinical success rates of $80-90 \%$ [4,7-9]. Although there are no randomized clinical trials comparing SEMS to EBD, the clinical response to SEMS appears to be more durable compared to EBD alone [9]. Moreover, SEMS can be effective in refractory cases that have failed previous $\operatorname{EBD}[9,10]$. A retrospective study of 10 patients with pyloric stenosis treated with SEMS reported $90 \%$ clinical success rate over a mean follow-up of 11 months, with half of the patients having previously failed EBD [9]. 


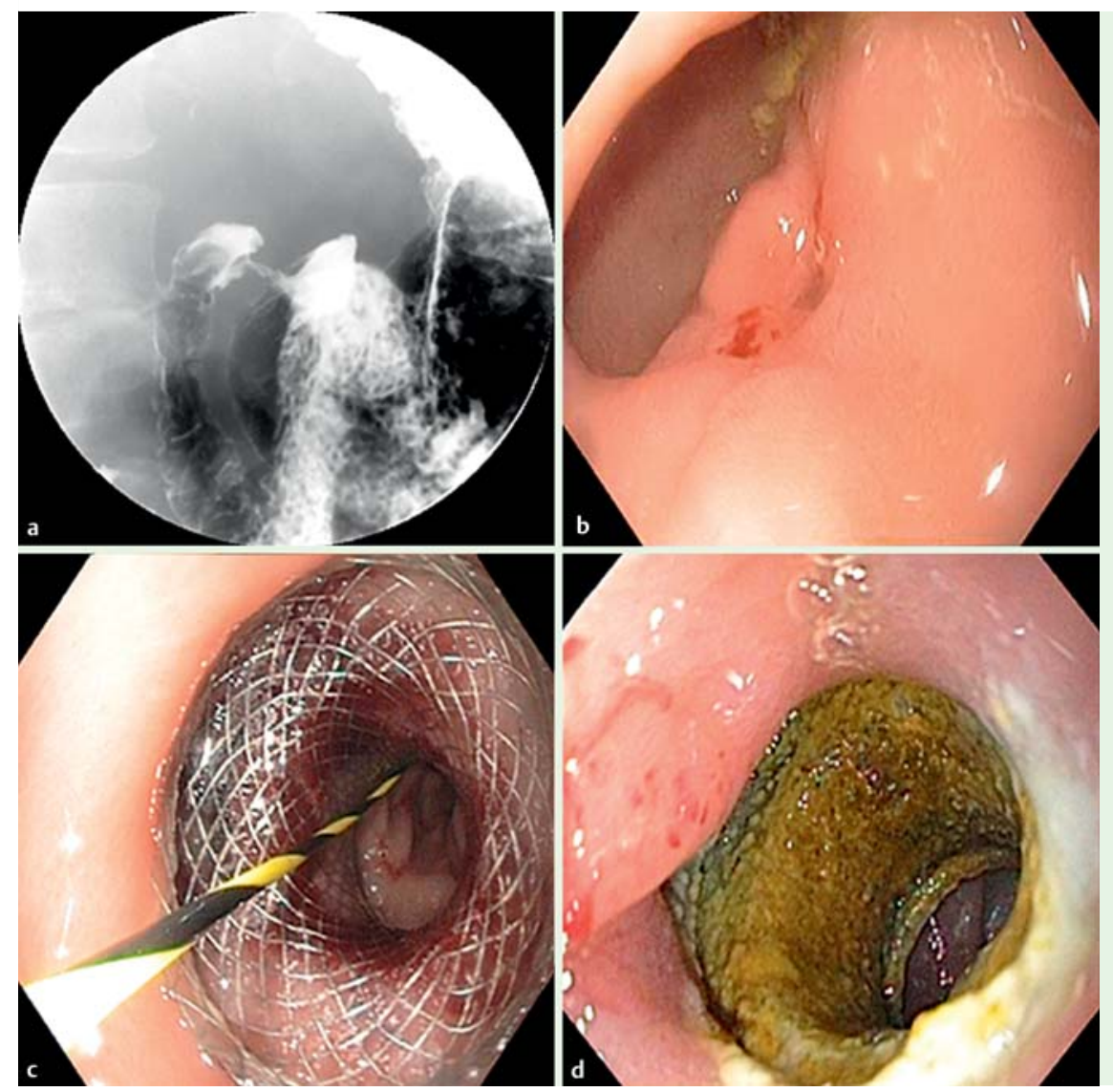

Fig. 2 a Contrast study demonstrating the stricture. $\mathbf{b}$ Endoscopic view of the stricture. c The proximal flange was opened inside the gastric antrum. d At 3-month follow-up, the stent was easily removed by grasping the proximal end with a rattooth forceps.
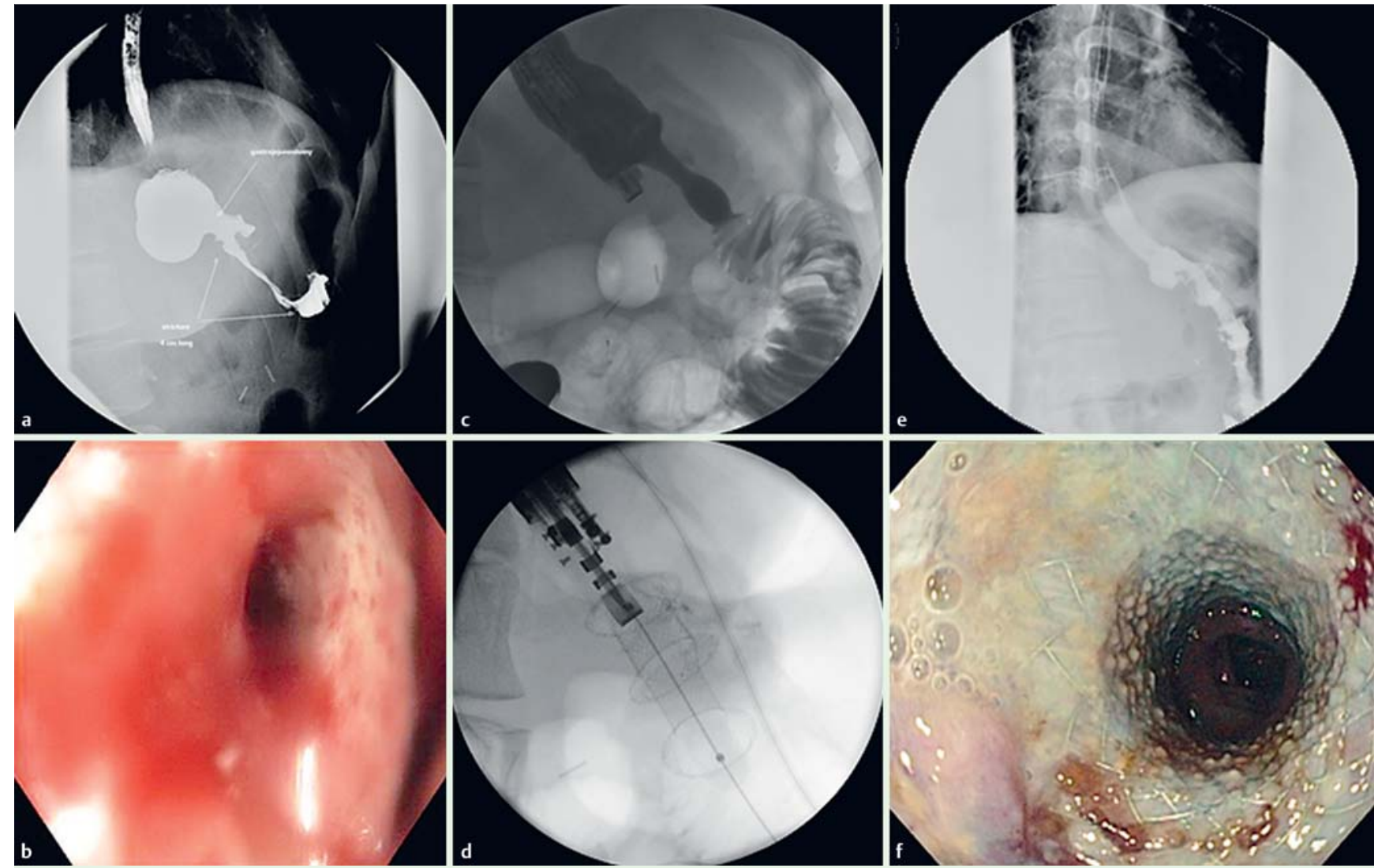

Fig. 3 a Contrast-study demonstrating the anastomotic stricture. $\mathbf{b}$ Endoscopic view of the stricture. $\mathbf{c}$ The distal flange of the stent was partially opened inside the Roux limb stricture. $\mathbf{d}$ To fully bridge the $4-\mathrm{cm}$ ischemic stricture, a second stent was placed inside the first one, with the distal flange of the stent in the jejunum and the proximal flange inside the lumen of the first stent. e A follow-up upper gastrointestinal series after 6 weeks showed a widely patent gastrojejunostomy with free flow of contrast to the Roux limb. $\mathbf{f}$ Endoscopic view demonstrating excellent stent position at follow-up endoscopy. 

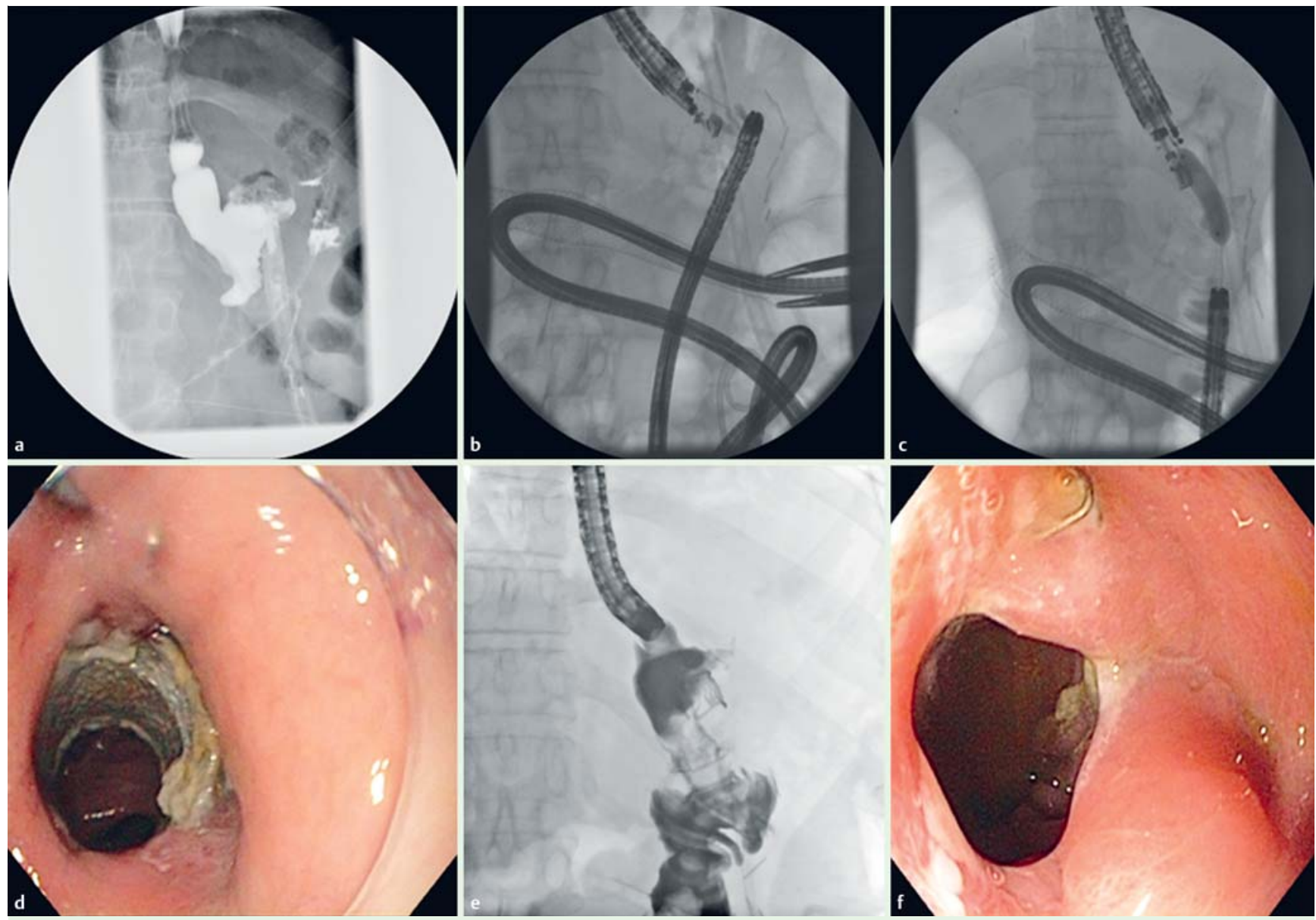

Fig. 4 a Contrast study demonstrating anastomotic leak at the gastric vertical staple line and complete gastrojejunostomy stricture. b Rendezvous endoscopic approach with single-balloon enteroscope inserted via the excluded stomach. $\mathbf{c}$ The echolinear EUS scope was simultaneously advanced to the gastric pouch. d Lumen-apposing, double-flanged, fully-covered SEMS, $15 \mathrm{~mm}$ in diameter, was deployed to create a new gastrojejunal anastomosis. e Contrast injection showing excellent seal of this newly created anastomosis with good flow of contrast into the Roux limb. $\mathbf{f}$ Stent endoscopically removed at 8 weeks demonstrating well-healed patent anastomosis.

Common adverse events associated with fcSEMS placed for benign strictures include migration and intolerance. A study of 22 patients with benign pyloric channel strictures treated with fcSEMS reported a migration rate of 63\% [4]. Partially covered SEMS have a lower migration rate, but are more difficult to remove due to tissue ingrowth [9]. Reported migration rates of SEMS in benign colorectal strictures range from $31 \%$ to $60 \%$ [11, 12]. A concern with the use of traditional SEMS for benign strictures, especially colonic, is the increased risk of perforation. In a meta-analysis of 4086 patients who underwent colorectal stent placement, the perforation rate was significantly higher for benign compared with malignant strictures (18.4\% vs. $7.5 \%$ ) [13]. LA-SEMS designed for EUS-guided deployment have design features making them suitable for treatment of benign strictures $[14,15]$. Anti-migratory flanges, short saddle, and moderate radial force may decrease the risk of migration and improve patient tolerance, allowing for a longer duration of therapy. In our series, none of the patients developed any stent-related symptoms and, in two patients, the stents were left in place permanently. Design modifications would enhance the use of LA-SEMS for management of benign gastrointestinal strictures. The current delivery system is optimized for delivery during EUS, and when deployed via a forward-viewing therapeutic channel endoscope, the stent's deployment handle requires stabilization by a second operator to prevent inadvertent deployment of the entire stent distal to the stricture ( Fig.1 b). A range of saddle lengths and larger stent diameters would improve the applicability of these devices.

The limitations of our study include the small number of patients, absence of a control group, subjective interpretation of clinical outcomes, and short duration of follow-up.Despite these limitations, our series adds to the one previous case report [16] describing the use of LA-SEMS in a benign stricture, and demonstrates the feasibility and potential safety and efficacy of LASEMS for management of various types of benign gastrointestinal stenoses. Prospective comparative trials of conventional SEMS, LA-SEMS, and balloon dilatation are warranted. 


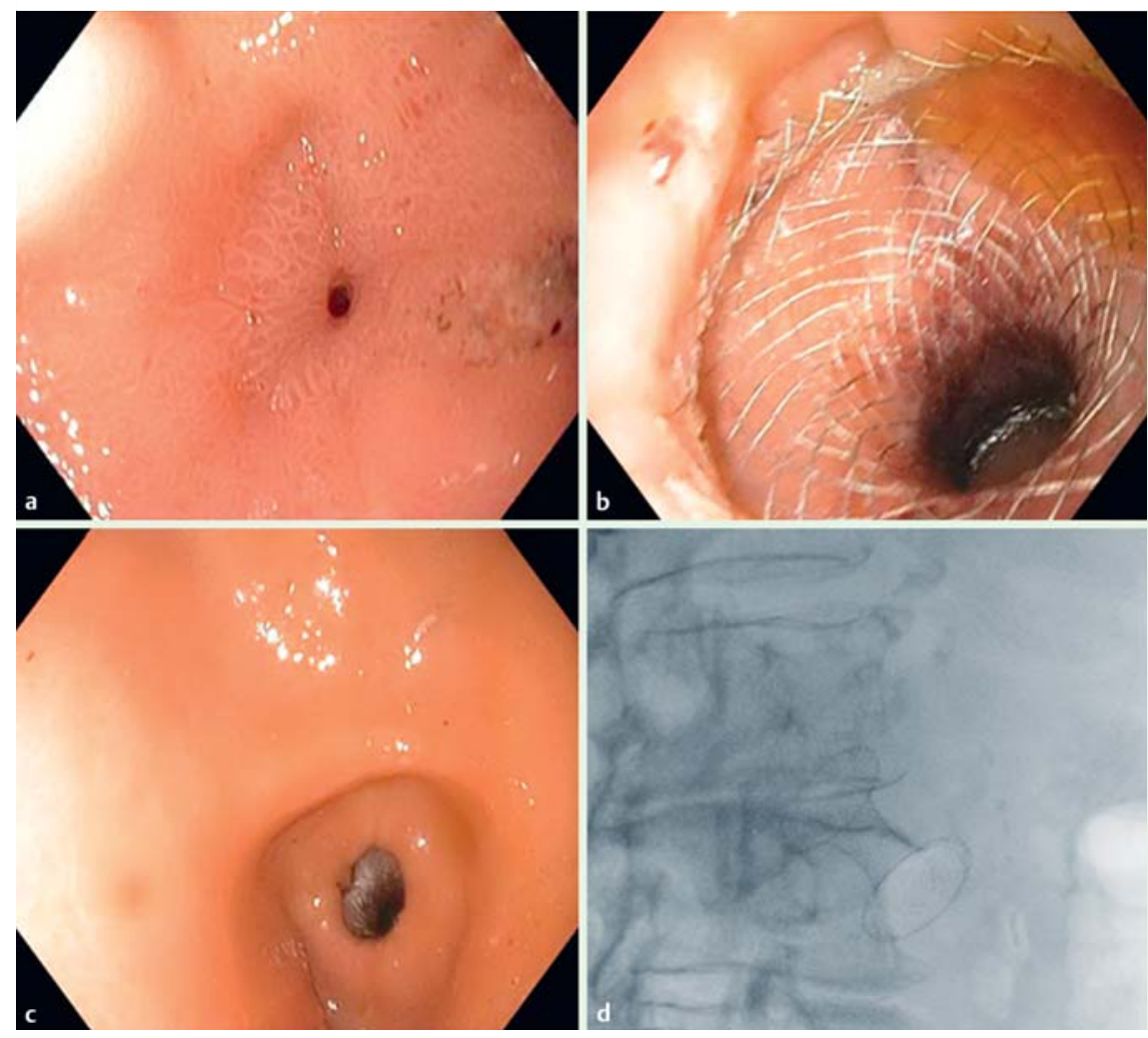

Fig. 5 a Short, tight, benign gastroduodenal stricture. b, c Endoscopic view of lumen-apposing, double-flanged, fully covered SEMS in the pyloric channel. $\mathbf{d}$ Stent lumen dilated to an internal diameter of $12 \mathrm{~mm}$ using a wire-guided hydrostatic dilation balloon.

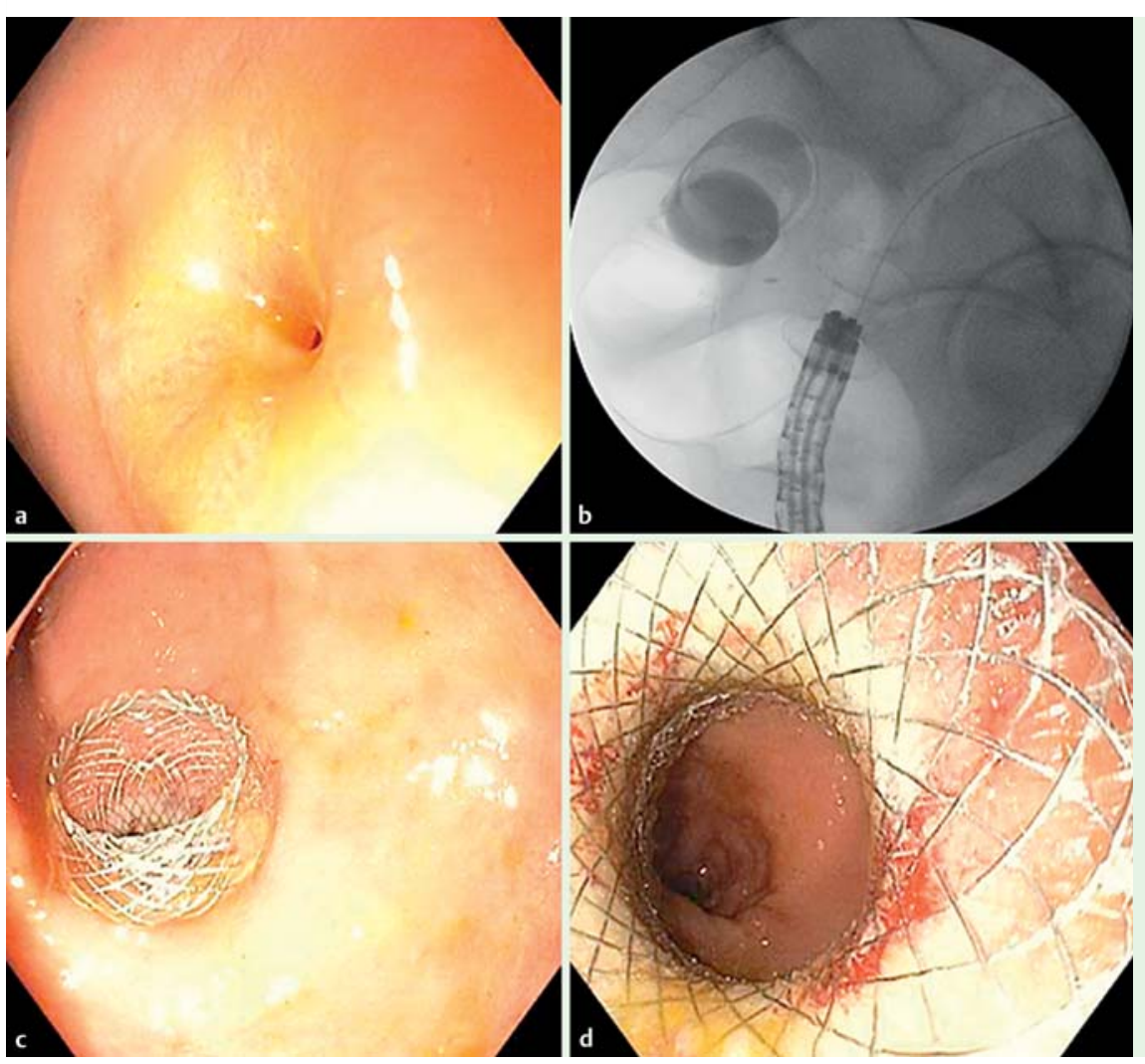

Fig. 6 a Endoscopic view of the tight anastomotic stricture. b Fluoroscopic image showing guidewire placement before stent deployment. $\mathbf{c}$ Endoscopic view of the proximal stent flange immediately after deployment. $\mathbf{d}$ Final stent position after balloon dilation of the SEMS lumen to $12 \mathrm{~mm}$. 


\section{Competing interests: None}

\section{References}

1 DiSario JA, Fennerty MB, Tietze CC et al. Endoscopic balloon dilation for ulcer-induced gastric outlet obstruction. Am J Gastroenterol 1994; 89: 868

2 Boylan JJ, Gradzka MI. Long-term results of endoscopic balloon dilatation for gastric outlet obstruction. Dig Dis Sci 1999; 44: 1883

3 Tringali A, Didden P, Repici A et al. Endoscopic treatment of malignant gastric and duodenal strictures: a prospective, multicenter study. Gastrointest Endosc 2014; 79: 66

4 Choi WJ, Park J-J, Park J et al. Effects of the temporary placement of a self-expandable metallic stent in benign pyloric stenosis. Gut Liver 2013; 7: 417-422

5 Vanbiervliet G, Bichard P, Demarquay JF et al. Research Committee of the French Society of Digestive Endoscopy (SFED). Fully covered selfexpanding metal stents for benign colonic strictures. Endoscopy 2013; 45: $35-41$

6 Holm AN, de la Mora Levy JG, Gostout CJ et al. Self-expanding plastic stents in treatment of benign esophageal conditions. Gastrointest Endosc 2008; 67: 20-25

7 Dormann AJ, Deppe H, Wigginghaus B. Self-expanding metallic stents for continuous dilatation of benign stenoses in gastrointestinal tract: first results of long-term follow-up in interim stent application in pyloric and colonic obstructions. Z Gastroenterol 2001; 39: 957-960

8 Han HW, Lee IS, Park JM et al. Self-expandable metallic stent therapy for a gastrointestinal benign stricture. Korean J Gastrointest Endosc 2008; $37: 1-6$
9 Heo J, Jung MK. Safety and efficacy of a partially covered self-expandable metal stent in benign pyloric obstruction. World J Gastroenterol 2014; 20: 16721 - 16725

10 Park S, Chun HJ, Keum B et al. Successful salvage treatment of peptic duodenal stenosis with repeat insertion of self-expanding stent after failed balloon dilation. Endoscopy 2011; 43: E187-E188

11 Park $\mathrm{CH}$, Yoon JY, Park SJ et al. Clinical efficacy of endoscopic treatment for benign colorectal stricture: balloon dilatation versus stenting. Gut Liver 2015; 9: 73-79

12 Attar A, Maunoury $V$, Vahedi K et al. GETAID. Safety and efficacy of extractible self-expandable metal stents in the treatment of Crohn's disease intestinal strictures: a prospective pilot study. Inflamm Bowel Dis 2012; 18: 1849 - 1854

13 van Halsema EE, van Hooft JE, Small AJ et al. Perforation in colorectal stenting: a meta-analysis and a search for risk factors. Gastrointest Endosc 2014; 79: 970-982

14 Itoi T, Binmoeller KF, Shah J et al. Clinical evaluation of a novel lumenapposing metal stent for endosonography-guided pancreatic pseudocyst and gallbladder drainage (with videos). Gastrointest Endosc 2012; 75: $870-876$

15 Shah RJ, Shah JN, Waxman I et al. Safety and efficacy of endoscopic ultrasound-guided drainage of pancreatic fluid collections with lumenapposing covered self-expanding metal stents. Clin Gastroenterol Hepatol 2015; 13: 747-752

16 Gornals JB, Albines G, Trenti $L$ et al. EUS-guided recanalization of a complete rectal anastomotic stenosis using a lumen-apposing metal stent. Gastrointest Endosc [Epub 2015 June 9] 